\title{
Stress performance of embedded carbon fiber reinforced plastics plate consolidated reinforced concrete structure
}

\author{
Hua Zhu \\ School of Civil Engineering, Yancheng Institute of Technology, Yancheng, Jiangsu, 224051, China \\ buazbu74@126.com
}

\begin{abstract}
With the development of the building industry, various novel building materials have emerged. Modern buildings requires higher on performance of building materials, and the performance of old buildings has not been able to keep up the pace of the times. Extending the service time of old buildings by repairing and reinforcing is inevitable. In this study, 10 reinforced concrete beams including 2 ordinary reinforced concrete beams and 8 carbon fiber reinforced plastics (CFRP) plate reinforced test beams were manufactured. Three-dimensional finite element model was established using finite element software to simulate and compare the stress performance of the strengthening beams with different number of CFRP plate, size, number of groove and shear span ratio. The results demonstrated that the ultimate carrying capacity of the embedded CFRP plate reinforced beams was obviously superior to that of the ordinary reinforced concrete beams; two plates and two grooves were appropriate; the larger the shear span ratio, the better the bearing performance and the smaller the deformation. CFRP plate consolidated reinforced concrete can effectively stabilize buildings which need repairing and reinforcement.
\end{abstract}

KEYWORDS. CFRP plate consolidation; Reinforced concrete; Threedimensional finite element model; Stress performance.

\section{OPEN ACCESS}

Citation: Zhu, H., Stress performance of embedded carbon fiber reinforced plastics plate consolidated reinforced concrete structure, Frattura ed Integrità Strutturale, 46 (2018) 361-370.

Received: 25.07 .2018

Accepted: 12.09 .2018 Published: 01.10.2018

Copyright: (C) 2018 This is an open access article under the terms of the CC-BY 4.0, which permits unrestricted use, distribution, and reproduction in any medium, provided the original author and source are credited.

\section{INTRODUCTION}

$\mathrm{W}$ ith the acceleration of urbanization, the performance of many old buildings has not been able to satisfy the requirements of the society. Therefore reinforcement is needed to recover their performance. The emergence of novel building materials provides a better choice for building reinforcement. Fiber reinforce plastic (FRP) has favorable mechanical performance and corrosion resistance performance. Embedded Carbon Fiber Reinforced Plastics (CFRP) plate reinforcement is a prospective method in the reinforcement of reinforced concrete beams. Motavalli et al. [1] made multi-aspect studies on the development of CFRP plate in the field of concrete. They developed 
a gradient prestressing technique without end anchorage plates and investigating confinement technique using nonlaminated thermoplastic CFRP straps. Raoof et al. [2] compared the flexural properties of Textile-reinforced mortar (TRM) versus fibre-reinforced polymers (FRP) and found that FRP was more superior in improving the flexural bearing capacity of reinforced concrete beams than TRM through experiments. To analyze the effect of CFRP in enhancing the carrying capacity of beams during bending, Khelifa et al. [3] developed a numerical program to simulate the bending behaviors of beams. Rezazadeh M et al. [4] designed an experimental procedure to evaluate the influence of prestress technology on the bending performance of the embedded CFRP plate consolidated reinforced concrete beams and found that prestressing could improve the load carrying capacity corresponding to the concrete cracking and steel yielding initiations.

After reviewing the articles concerning about CFRP consolidated reinforced concrete beams and reinforced concrete slab, Jumaat et al. [5] put forward a simple CFRP reinforcement method to strengthen the negative moment regions of continuous $\mathrm{T}$ beams and attempted to address an important practical issue that is encountered in strengthening the negative moment region of RC continuous T beam. Dias et al. [6] studied the effect of CFRP in reinforcing reinforced concrete beams in aspects of the percentage and inclination of CFRP laminates and percentage of stirrups and found that embedded CFRP had better efficacy in strengthening reinforced concrete beams. In this study, the finite element analysis software ANSYS was used for simulation, and the simulated values were compared with the test values to verify the effectiveness of the model; moreover the stress performance of CFRP plates in different structures was also simulated using finite element model to analyze the influence of different number of CFRP plate, grooving mode and shear span ratio on beams and explore the best reinforcement way of embedded CFRP plate.

\section{EMBEDDED CFRP PLATE}

$\mathrm{F}$ $\mathrm{RP}$ which is composed of fiber materials and resin is prone to be installed on irregular surface and has advantages of higher strength and strong corrosion resistance [7,8]. It was found that the application of FRP can recover or improve the original strength of beams [9]. FRP can be divided into CFRP, glass fiber reinforced plastics (GFRP), aromatic polyamide fiber reinforced plastics (AFRP), etc. CFRP has stronger tensile and bending resistance compared to other materials.

FRP reinforcement includes FRP surface pasting method and FRP embedded reinforcement. The procedures of embedded reinforcement are as follows. Firstly, concrete cover was grooved. After the dust in the groove was cleaned, half of the groove was filled with cementing material, for example, resin. Then FRP was added and pressed.

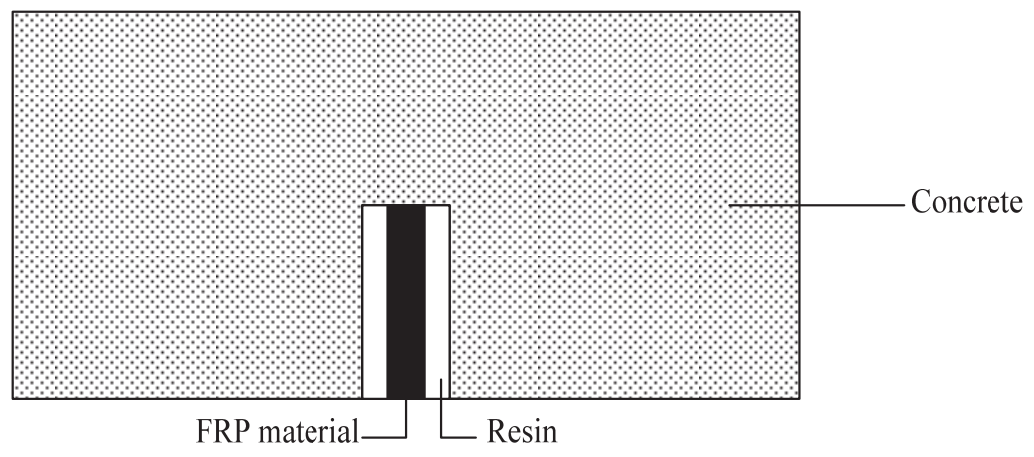

Figure 1: The schematic diagram of embedded reinforcement.

FRP reinforcement can effectively strengthen the bending and shear resistance performance of reinforced concrete beams [10], which has many advantages compared to other reinforcement methods.

Embedded FRP avoids contact with the outside world, i.e., reduce the influence of external environment on the performance of materials.

The complete contact of FRP and binding materials reduces the possibilities of debonding failure.

It is suitable for strengthening the negative moment region of structural components.

When FRP reinforcement is used, the workload of processing concrete surface is light, saving time and cost. 


\section{ANALYSIS ON THE FAILURE MODE OF EMBEDDED CFRP PLATE CONSOLIDATED REINFORCED CONCRETE BEAMS}

\section{Bending failure}

T T T hen the length of CFRP plate is enough and its binds well with concrete, strengthening beams may have bending failure, i.e, the shear bearing capacity of strengthening beams is larger than the bending bearing capacity, tensile reinforcement yields, and concrete is crushed or CFRP plate breaks. When the crushing of concrete and the fracture of CFRP plate happen simultaneously, then [11]:

$$
A_{f}^{*}=\frac{0.8\left(\frac{\varepsilon_{c u}}{\varepsilon_{c u}+\varepsilon_{f u}}\right) f_{c} b b-f_{y} A_{s}}{f_{f}}
$$

where $\varepsilon_{f u}$ stands for the ultimate strain of CFRP plate, $\varepsilon_{c u}$ stands for the ultimate strain of concrete, b stands for the width of beam section, $h$ stands for the height of beam section, fc stands for the design value of cube compressive strength of concrete under uniaxial stress, fy stands for the design value of tensile strength of rebars, and As stands for the cross sectional area of rebars.

When $A_{f}>A_{f}^{*}$, concrete is crushed; when $A_{f}<A_{f}^{*}$, CFRP plate fractures.

\section{Shear failure}

When the stirrup ratio is not enough or shear is the first to exceed other resistances, strengthening beams are very likely to have shear failure. The shear failure of strengthening beams indicates beams have excellent bending resistance, and the values of CFRP are given full play.

\section{Debonding failure}

Debonding failure is a special failure mode in embedded CFRP plate reinforcement method and also the main failure mode. CFRP plate reinforcement includes the mutual contact of three materials, i.e., contact between CFRP plate and binding materials and contact between binding materials and concrete. The hardness and strength of binding materials are very likely to decrease with the increase of temperature [12]. The main manifestations of failure include failure of connection between CFRP plate and resin, failure of connection between resin and concrete, failure of resin and failure of concrete.

\section{FINITE ELEMENT ANALYSIS}

\section{Establishment of finite element model}

7 inite element method which is a practical numerical calculation method has been applied in many fields. In this study ANSYS was used for simulating and analyzing embedded CFRP plate consolidated reinforced beams.

\section{Concrete}

SOLID65 element in ANSYS was used for simulating concrete material. The cracking of concrete was observed via the equivalent value of plastic strain. Damaged plasticity model (dilatancy angle: $45^{\circ}$, eccentricity ratio: 0.1 , viscous parameter: 0.005) was used. During modeling, a rectangle with a size of $150 * 300 \mathrm{~mm}$ was drawn, and then it was stretched for $2400 \mathrm{~mm}$ to form a concrete beam.

\section{Rebars}

LINK8 element was used for simulating rebars. The rebars born under uniaxial tension and compression and could move freely in the directions of $\mathrm{X}, \mathrm{Y}$ and $\mathrm{Z}$. The plasticity, expansion and deformation of rebars were simulated. The parameters of rebars are shown in Tab. 1. 


\begin{tabular}{cccc}
\hline $\begin{array}{c}\text { Materials } \\
\text { Specification } \\
\text { Elasticity } \\
\text { modulus } E_{s} \\
\left(\times 10^{5} \mathrm{~N} / \mathrm{mm}^{2}\right)\end{array}$ & $\begin{array}{c}\text { Compressed rebar } \\
\text { HRB4002 } \Phi_{10}\end{array}$ & $\begin{array}{c}\text { Tension rebar } \\
\text { HRB4002 } \Phi_{14}\end{array}$ & $\begin{array}{c}\text { Stirup } \\
\text { HPB300 } \Phi_{8}\end{array}$ \\
\hline $\begin{array}{c}\text { The design value of } \\
\text { tensile strength } \\
f_{y}\left(\mathrm{~N} / \mathrm{mm}^{2}\right)\end{array}$ & 2.00 & 2.00 & 2.20 \\
\hline $\begin{array}{c}\text { The design value of } \\
\text { compressive } \\
\text { strength }\end{array}$ & 360 & 360 & 280 \\
$f_{y}^{\prime}\left(\mathrm{N} / \mathrm{mm}^{2}\right)$ & 360 & 360 & 280 \\
\hline
\end{tabular}

Table 1: The parameters of rebars.

\section{CFRP plate and binding material}

CFRP plate and binding material were regarded as a whole and simulated using SOLID45 element. The ultimate tensile strength of CFRP plate $f_{f u}$ was $2860 \mathrm{~N} / \mathrm{mm}^{2}$, elasticity modulus $E_{f f}$ was $1.47 \times 10^{5} \mathrm{~N} / \mathrm{mm}^{2}$, and Poisson's ratio was 0.3 . The Poisson's ratio and elasticity modulus of binding material was 0.25 and $3500 \mathrm{~N} / \mathrm{mm}^{2}$ respectively.

\section{Cushion block.}

To prevent stress concentration induced local damage, rigid cushion blocks were used at the support and loading points. It was simulated using SOLID45 element. The Poisson's ratio and elasticity modulus of cushion block was 0.3 and $2.0 \times$ $10^{5} \mathrm{~N} / \mathrm{mm}^{2}$.

\section{Modeling and solution process}

Mapping meshing was used. The position of node generation should ensure the sharing nodes of different materials were at the same position after connection. Taking the position of rebars and the size of groove as an example, concrete, resin and cushion blocks were divided into hexahedral element.

Nodes were established in the space firstly. Then rebars generated via the nodes. Plane net was established on the plane which the top of the beam and cushion blocks lie; after stretching, concrete and cushion blocks were established, and the position of groove should be left. After merging of the nodes, CFRP element was established at the pre-aside position for groove. Then mid-span symmetry was performed to simulate the whole beam.

Displacement control was used in the simulation process, and the maximum displacement value was $0.05 \mathrm{~m}$. After modeling, data were analyzed using finite element solver via Static. The calculation results were extracted using POST1.

\section{Design of component}

The size of the component was $150 \mathrm{~mm} * 300 \mathrm{~mm} * 2300 \mathrm{~mm}$. The calculated net span of the beam was $2100 \mathrm{~mm}$. The size of tension rebar of the test beam and erection rebar was $2 \Phi 25\left(\mathrm{~A}_{\mathrm{s}}=980 \mathrm{~mm}^{2}\right)$ and $2 \Phi 6.5\left(\mathrm{~A}_{\mathrm{s}}=65 \mathrm{~mm}^{2}\right)$ respectively. Unilateral stirrup reinforcement was used, and the reinforcement zone was $\Phi 6.5 @ 50$, and the nonreinforcement zone was $\Phi 6.5 @ 200$. The thickness of the protective layer at the lower layer of the concrete beam was $30 \mathrm{~mm}$, and the protective layer at the upper layer was $20 \mathrm{~mm}$.

\section{FINITE ELEMENT ANALYSIS RESULTS}

\section{Analysis of concrete failure}

he failure process of the strengthening beam was as follows. In the initial stage, the tension on the beam is shared by rebars, concrete and CFRP plate. With the increase of load, concrete in the tension zone fractured. In the middle stage, the stress on the rebars and CFRP plate became layer, and the tension mainly relied on rebars and CFRP plate. With the increase of the load, the rebars reached the yield stress. In the late stage, the strain on the CFRP 
plate increased, the stress on the rebars stopped increasing, bond slip happened to the rebars and concrete, the CFRP plate shouldered the main tension. At that moment, the ultimate carrying capacity and failure mode of the strengthening beam mainly depended on whether the binding between the CFRP plate and concrete was tight.

The main failure modes included crushing of concrete beam, fracture of CFRP plate, debonding of CFRP plate and binding materials, debonding of the protective layer of concrete and debonding of concrete and binding materials.

\section{Comparison between simulated values and test values}

To verify the accuracy of the finite element model, the analysis results of L1, L2 and L3 beams were firstly selected. The specific parameters of the beams are shown in Tab. 2 .

\begin{tabular}{cccc}
\hline $\begin{array}{c}\text { No. of test specimen } \\
\text { Width of CFRP } \\
\text { plate (mm) }\end{array}$ & L1 & L2 & L3 \\
$\begin{array}{c}\text { Number of CFRP } \\
\text { plate }(\mathrm{n})\end{array}$ & 10 & 10 & 10 \\
$\begin{array}{c}\text { The embedding } \\
\text { angle of CFRP plate }\end{array}$ & 6 & 4 & 4 \\
$\begin{array}{c}\text { Spacing between } \\
\text { CFRP plate }(\mathrm{mm}) \\
\begin{array}{c}\text { Depth of groove } \\
\quad(\mathrm{mm})\end{array}\end{array}$ & 100 & 90 & 90 \\
$\begin{array}{c}\text { Shear span } \\
\text { ratio }(\mathrm{a} / \mathrm{h} 0)\end{array}$ & 20 & 150 & 150 \\
\hline
\end{tabular}

Table 2: The parameters of the verified beams.

The mid-span vertical displacement of the model beam was extracted as the mid-span deflection of the beam. The 2-fold value of the reactive force at the cushion blocks was taken as the concentrated load of the beam. The load-deflection curve of the strengthening beam was drawn. The test values were compared with the simulated values to verify the accuracy of the model. The comparison results are shown in Fig. 2, 3 and 4.

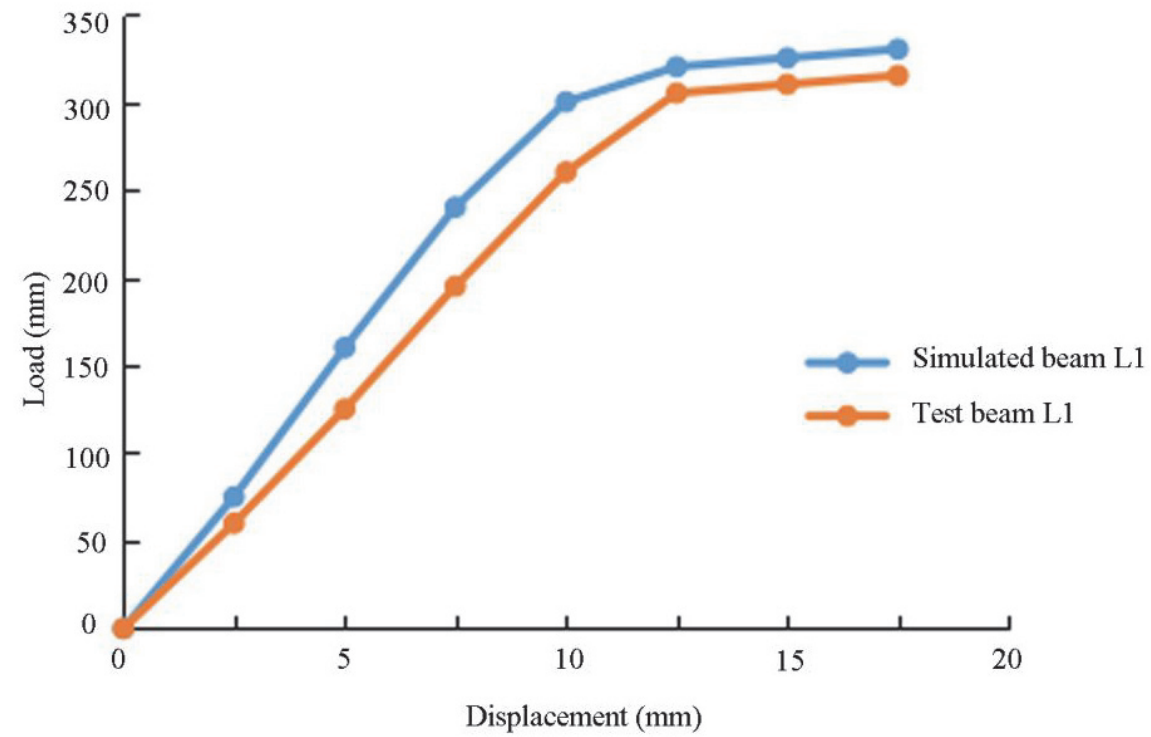

Figure 2: The load-deflection curve of L1.

It could be noted from the load-deflection curves that the differences between the simulated values and test values were small, suggesting the high accuracy of the finite element model. The comparison results of the ultimate load values of the test beams and simulated beams are shown in Tab. 3 . 


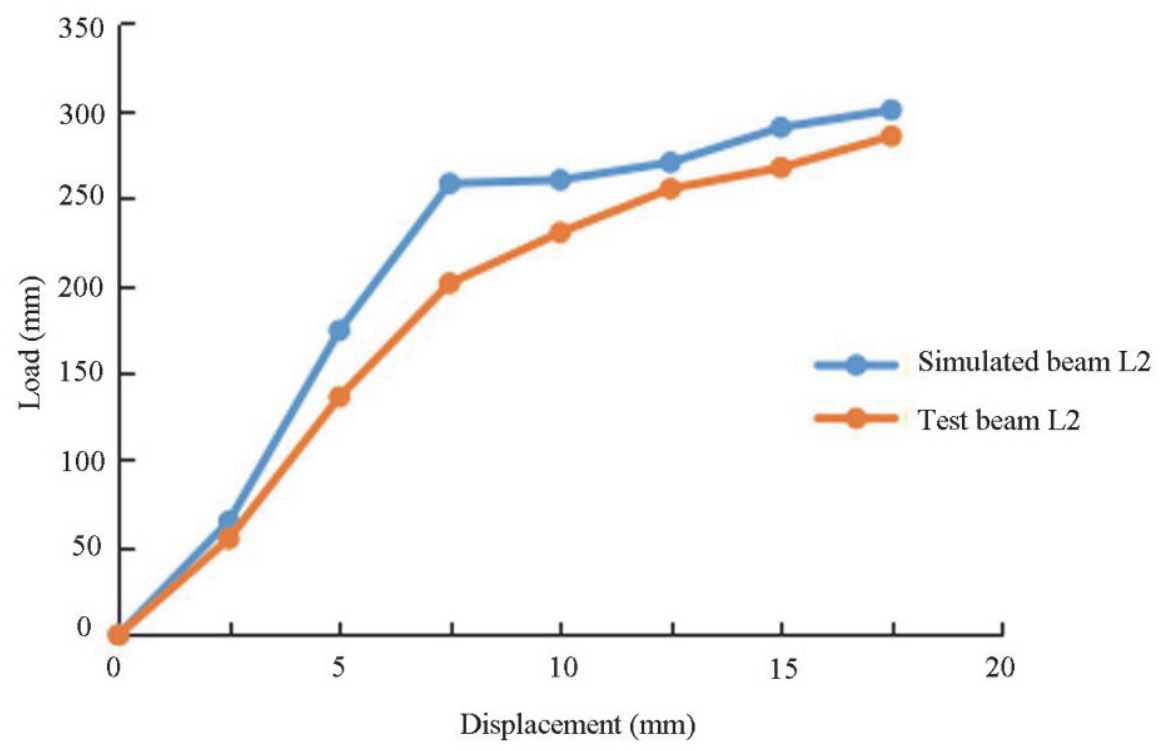

Figure 3: The load-deflection curve of L2.

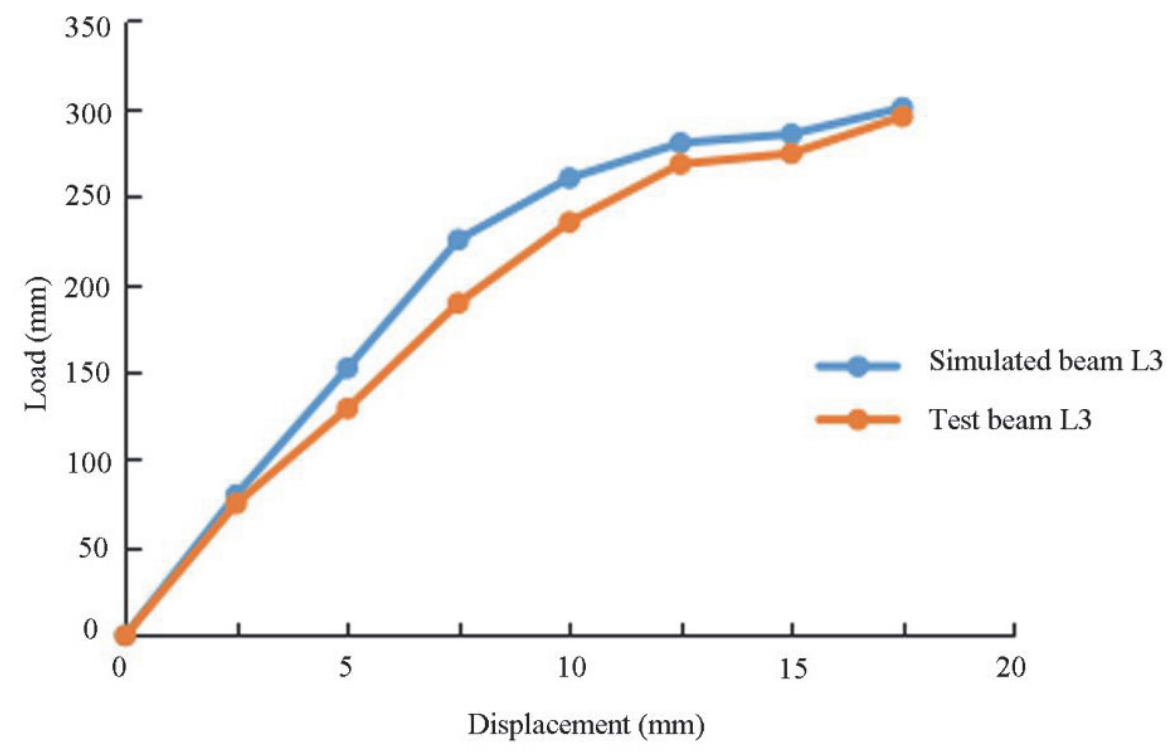

Figure 4: The load-deflection curve of L3.

\begin{tabular}{lccc}
\hline $\begin{array}{l}\text { No. of test specimen } \\
\text { The test value of the } \\
\text { ultimate load (KN) }\end{array}$ & L1 & L2 & L3 \\
$\begin{array}{l}\text { The simulated value } \\
\text { of the ultimate load } \\
(\mathrm{KN})\end{array}$ & 334.68 & 289.54 & 279.61 \\
Error (\%) & 339.02 & 308.52 & 286.37 \\
\hline
\end{tabular}

Table 3: The comparison of the test values and simulated values of the beams.

Tab. 3 suggests that the test values were close to the simulated values, and the errors were all lower than $10 \%$. The strains of the rebars and CFRP plates were analyzed using universal methods, and there were also small errors between the tested values and simulated values. The results suggested that the finite element model had a high accuracy. 


\section{ANALYSIS ON THE MECHANICAL PERFORMANCE}

$\mathrm{T}$ o determine the best reinforcement method of CFRP plate, different embedded CFRP plates were studied using finite element model. Taking reinforced concrete beam as an example, six reinforcement methods were designed to analyze and compare the mechanical performance of the beam. The model parameters are shown Tab. 4.

\begin{tabular}{|c|c|c|c|c|c|c|c|}
\hline $\begin{array}{l}\text { No. of test } \\
\text { specimen }\end{array}$ & $\begin{array}{l}\text { Reinforced } \\
\text { concrete } \\
\text { beam }\end{array}$ & A & B & $\mathrm{C}$ & $\mathrm{D}$ & $\mathrm{E}$ & $\mathrm{F}$ \\
\hline $\begin{array}{l}\text { Size of test } \\
\text { specimen } \\
(\mathrm{mm}) \\
\text { Size of }\end{array}$ & $\begin{array}{c}200 * 250 * \\
1800\end{array}$ & $\begin{array}{c}200 * 250 * \\
1800\end{array}$ & $\begin{array}{c}200 * 250 * \\
1800\end{array}$ & $\begin{array}{c}200 * 250 * \\
1800\end{array}$ & $\begin{array}{c}200 * 250 * \\
1800\end{array}$ & $\begin{array}{c}200 * 250 * \\
1800\end{array}$ & $\begin{array}{c}200 * 250 * \\
1800\end{array}$ \\
\hline $\begin{array}{l}\text { CFRP plate } \\
(\mathrm{mm})\end{array}$ & - & $1.2 * 20 * 1800$ & $1.2 * 20 * 900$ & $1.2 * 20 * 900$ & $1.2 * 20 * 600$ & $1.2 * 20 * 600$ & $1.2 * 20.900$ \\
\hline $\begin{array}{l}\text { Number of } \\
\text { CFRP plate } \\
\text { (n) }\end{array}$ & - & 1 & 2 & 2 & 3 & 3 & 2 \\
\hline $\begin{array}{l}\text { Number of } \\
\text { grooves (n) }\end{array}$ & - & 1 & 1 & 2 & 1 & 3 & 2 \\
\hline $\begin{array}{l}\text { Size of } \\
\text { groove } \\
(\mathrm{mm})\end{array}$ & - & $20 * 20 * 1800$ & $20 * 20 * 900$ & $20 * 20 * 900$ & $20 * 20 * 600$ & $20 * 20 * 600$ & $20 * 20 * 900$ \\
\hline $\begin{array}{l}\text { Shear span } \\
\text { ratio }(\mathrm{a} / \mathrm{h} 0) \\
\text { Spacing }\end{array}$ & - & 2.32 & 2.32 & 2.32 & 2.32 & 2.32 & 2.73 \\
\hline $\begin{array}{l}\text { between } \\
\text { grooves } \\
(\mathrm{mm})\end{array}$ & - & - & - & 80 & - & 60 & 80 \\
\hline
\end{tabular}

Table 4: The model parameters.

Fig. 5 shows the load-deflection curves of the strengthening beams of different kinds. With the increase of the load, the load-deflection curves of different beams gradually changed: the concrete at the bottom of the beam fractured, and the mechanical performance of the beam changed. The deflection of the strengthening beams increased slower than that of the non-strengthening beams, indicating that CFRP plate could effectively reduce the mid-span displacement of beams. Different reinforcement methods of beams had different influence on the carrying capacity and failure modes of beams. In the aspect of groove mode, the effect of multiple grooves and plates was better than that of single groove and multiple plates. CFRP plate could inhibit the growth of cracks, but too many grooves was not beneficial to the integral rigidity of beams; therefore two grooves was the best. In the aspect of shear span ratio, the larger the shear span ratio. Tab. 5 shows the ultimate carrying capacity, improvement amplitude and failure mode of the strengthening beams of different kinds. Under the same load, the mid-span displacement of the strengthening beams was smaller than that of the nonstrengthening beams. The improvement amplitudes of beam $\mathrm{C}$ and $\mathrm{F}$ was the largest, but beam $\mathrm{F}$ was more obvious. I indicated that the larger the shear span ratio, the better then reinforcement effect. As to the failure mode, beam $\mathrm{E}$ had bending failure, and the other beams had debonding failure. It might be because the increased number of grooves. Moreover debonding failure of the protective layer of concrete can be avoided only when the length of the CFRP plate was enough.

The CFRP plate, rebars and concrete strains of the reinforced beam, beam $\mathrm{C}$ and beam $\mathrm{F}$ were further compared, and the comparison results are shown in Fig. 6.

It could be noted from Fig. 6 that the strain value of the CFRP plate strengthening beam was larger than that of the reinforced concrete beam. Under the same load, the strain of the CFRP plate was larger than that of the rebars as the bottom tension was bore by the CFRP plates and rebars after the cracking of concrete, the relative distance of the CFRP plates was large, and the elasticity modulus was low. The strain of beam $\mathrm{F}$ was larger than the strain of beam $\mathrm{C}$, indicating that the larger the shear span ratio, the better the mechanical performance. 


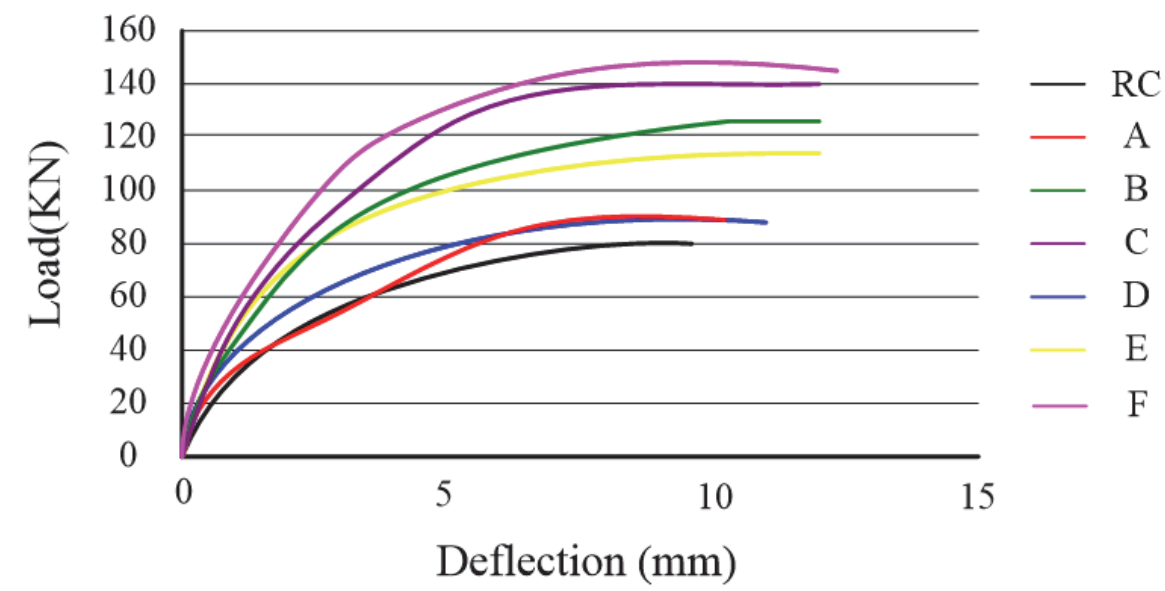

Figure 5: The load-deflection curve of different beams

\begin{tabular}{cccccccc}
\hline $\begin{array}{c}\text { No. of test } \\
\text { specimen } \\
\text { Ultimate }\end{array}$ & RC & A & B & C & D & E & F \\
$\begin{array}{c}\text { load }(\mathrm{KN}) \\
\text { Improvem } \\
\text { ent }\end{array}$ & 89 & 110 & 127 & 140 & 106 & 115 & 152 \\
$\begin{array}{c}\text { amplitude } \\
(\%)\end{array}$ & - & 23.6 & 42.7 & 57.3 & 19.1 & 29.21 & 70.79 \\
$\begin{array}{c}\text { Failure } \\
\text { mode }\end{array}$ & - & 1 & 2 & 2 & 3 & 2 & 2 \\
\hline
\end{tabular}

Table 5: The results of different beams.

Note: 1. Crushing failure of concrete beams; 2. Debonding failure of concrete and binding materials; 3 : debonding failure of the protective layer of concret.e

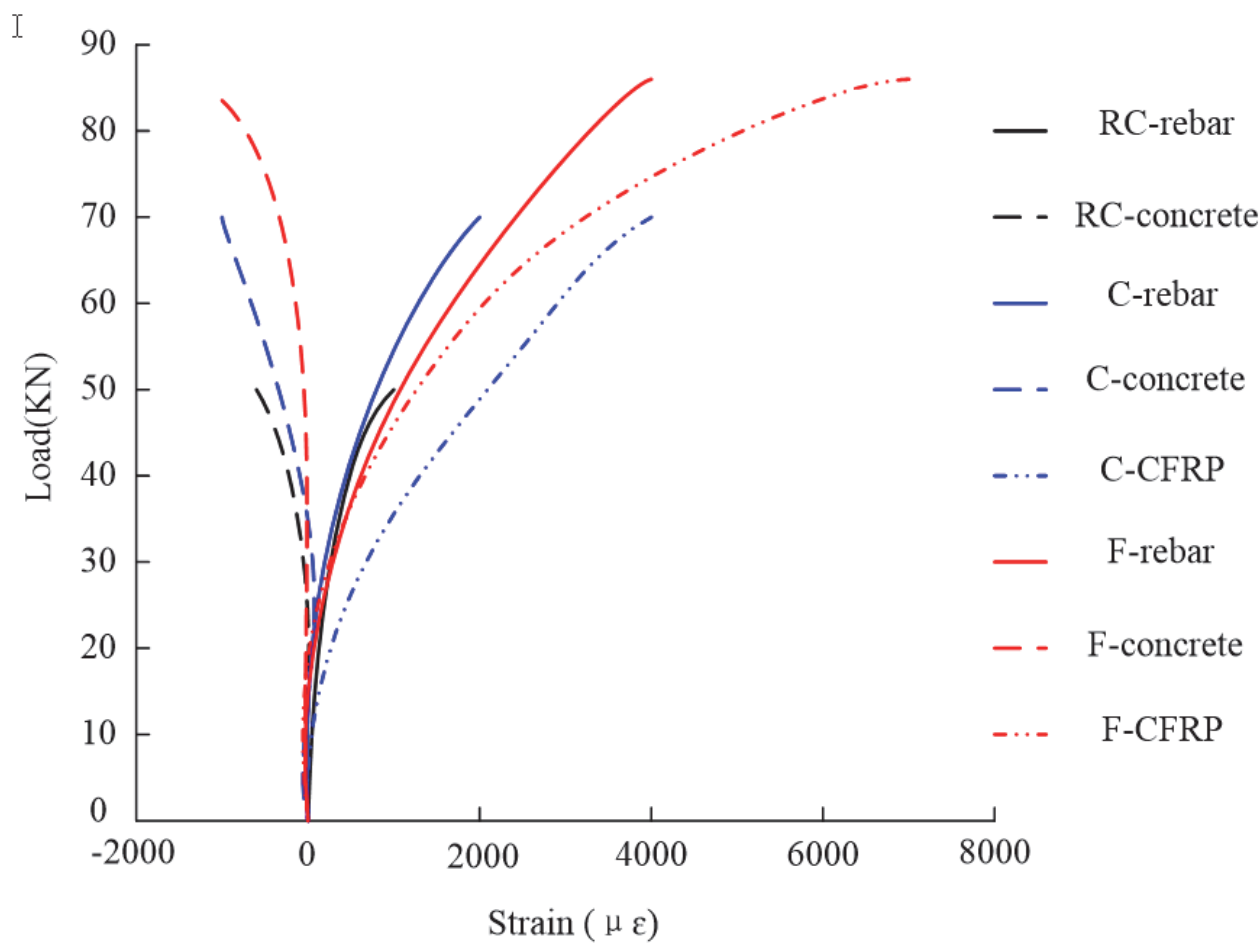

Figure 6: The comparison results of strains of different beams. 


\section{DISCUSSION AND CONCLUSION}

$\mathrm{F}$ $\mathrm{RP}$ as a novel building material suggests favourable performance in reinforcing reinforced concrete beams. To prevent the failure of binding materials, embedded CFRP plate strengthening is an advantageous method [13]. To fully understand the performance of CFRP plate, multi-aspect studies need to be made. The application of finite element software can reduce test materials and workload. Many scholars have studied the functions of finite element software in the simulation of CFRP plate strengthening. Dirar et al. [14] analyzed the shear capacity of reinforced concrete beams using finite element analysis method and compared the simulated values and test values of shear force, shear force-deflection curve, crack mode and failure mode via modeling to understand the shear capacity. Taghia et al. [15] explored the influence of CFRP plate on reinforced concrete short columns using finite element software, studied different aspects of constraint effect such as difference of sectional dimension, number of carbon fiber cloth and volume ratio of carbon fiber cloth, and found that outside sticking of carbon fiber cloth was quite effective in improving the axial strength and ductility of concrete short columns. In this study, the model was established using ANSYS. To verify the reliability of the model, the test values and simulated values of three beams were compared, and it was found that the two groups of data basically fitting. The existence of error might be because the test beams were affected by factors such as temperature and proportion of concrete, the finite element model ignored the bond slipping between different interfaces of the beams, and partial parameters were excessively ideal. But overall, the results could verify that the finite element model had high accuracy and reliability.

To study the mechanical performance of embedded CFRP plate reinforcement method, six reinforcement methods which involved different length of CFRP plate, number of CFRP plate, number of grooves and shear span ratio were compared. The results demonstrated that different reinforcement methods had different influences on the carrying capacity and failure mode of beams; proper increase of length of CFRP plate could avoid the debonding failure of the protective layer of concrete; multiple plates and grooves could increase the surface of plates and inhibit the growth of cracks at the bottom of concrete, but too many grooves was not beneficial to the integral rigidity of beams and might lead to decrease of the ultimate carrying capacity (for example, beam E); the larger the shear span ratio, the higher the ultimate carrying capacity of beams and the lower the possibility of deformation (for example, beam F). The beams except beam A had debonding failure, which might be because the sufficient length of anchoring of the CFRP plates of beam A reduced the possibilities of debonding failure. It indicated that the embedded length of the CFRP plate might be in an obvious correlation with the possibilities of debonding failure. The comparison of strain between the rebars, concrete and CFRP plate suggested that embedded CFRP plate reinforcement was significantly effective in increasing the strain of the beams, and the strain of the CFRP plate was larger than that of the rebars. In conclusion, embedded CFRP plate strengthening was effective in enhancing the mechanical performance of reinforced concrete beams.

Embedded CFRP plate strengthening beams with favourable mechanical performance has a broad development prospect in repairing old buildings. In this study, the mechanical performance of the beams which applied different strengthening methods was compared in aspects of the number, size, grooving mode and shear span ratio of the CFRP plate after the effectiveness of the model was verified. The results demonstrated that the ultimate carrying capacity of the embedded CFRP plate strengthening beams was significantly superior to that of ordinary reinforced concrete beams, the reinforcement method of two CFRP plates and two grooves was the best, and the larger the shear span ratio, the higher the carrying capacity and the lower the possibility of deformation. Embedded CFRP reinforcement technology has more possibilities, and its application values need to be explored through more studies in the future.

\section{REFERENCES}

[1] Motavalli, M., Czaderski, C. and Pfyl-Lang, K. (2011). Prestressed CFRP for Strengthening of Reinforced Concrete Structures - Recent Developments at Empa Switzerland. Journal of Composites for Construction, 15(2), pp. 194205.

[2] Raoof, S.M., Koutas, L.N. and Bournas, D.A. (2017). Textile-reinforced mortar (TRM) versus fibre-reinforced polymers (FRP) in flexural strengthening of RC beams. Construction \& Building Materials, 151, pp. 279-291.

[3] Khelifa, M. and Celzard, A. (2014). Numerical analysis of flexural strengthening of timber beams reinforced with CFRP strips. Composite Structures, 111(1), pp. 393-400.

[4] Rezazadeh, M., Costa, I. and Barros, J. (2014). Influence of prestress level on NSM CFRP laminates for the flexural strengthening of RC beams. Composite Structures, 116 (1), pp. 489-500. 
[5] Jumaat, M.Z., Rahman, M.M. and Alam, M.A. (2010). Flexural strengthening of RC continuous T beam using CFRP laminate: A review. International Journal of Physical Sciences, 5(6), pp. 619-625.

[6] Dias, S.J.E. and Barros, J.A.O. (2012). NSM shear strengthening technique with CFRP laminates applied in highstrength concrete beams with or without pre-cracking. Composites Part B, 43(2), pp. 290-301.

[7] Elchalakani, M. (2014). CFRP strengthening and rehabilitation of degraded steel welded RHS beams under combined bending and bearing. Thin-Walled Structures, 77(4), pp. 86-108.

[8] Belarbi, A. and Acun, B. (2013). FRP Systems in Shear Strengthening of Reinforced Concrete Structures. Procedia Engineering, 57(1), pp. 2-8.

[9] Parvin, A. and Brighton, D. (2014). FRP Composites Strengthening of Concrete Columns under Various Loading Conditions. Polymers, 6(4), pp. 1040-1056.

[10] Burke, P.J., Bisby, L.A. and Green, M.F. (2013). Effects of elevated temperature on near surface mounted and externally bonded FRP strengthening systems for concrete. Cement \& Concrete Composites, 35(1), pp. $190-199$.

[11] Ou, J.P., Wang, B., He, Z., Zhang, X. and Qian, M. (2004). Load-deflection response of concrete beams reinforced with FRP bars. Advances in Structural Engineering, 7(5), pp. 427-436.

[12] Stratford, T.J. and Bisby, L.A. (2012). Effect of Warm Temperatures on Externally Bonded FRP Strengthening. Journal of Composites for Construction, 16(3), pp. 235-244.

[13] Wu, Z., Iwashita, K., Sun, X. and Kobayashi, A. (2010). Development of structural strengthening method with prestressed near-surface mounted CFRP tendons. Kozo Kogaku Ronbunshu A, 56, pp. 630-643.

[14] Dirar, S., Lees, J.M. and Morley, C. (2013). Phased Nonlinear Finite-Element Analysis of Precracked RC T-Beams Repaired in Shear with CFRP Sheets. Journal of Composites for Construction, 17(4), pp. 476-487.

[15] Taghia, P. and Bakar, S.A. (2013). Mechanical behaviour of confined reinforced concrete-CFRP short column- based on finite element analysis. World Applied Sciences Journal, 24(7), pp. 960-970. 